\title{
Resistance and Gain of the Microchannel Plate (MCP) detector as a function of temperature
}

O. B. Chassela*a, A. Grigoreiva , A. Fedorova, N. Andréa, E. Le-Comtea, J. Rouzauda, P. Spezzigu ${ }^{b}$

aIRAP, CNRS, UPS, CNES, Université de Toulouse, Toulouse, France, bINTRASPEC TECHNOLOGIES, Toulouse, France 


\section{Outline}

- The MCP detector

- Motivations

- Backgrounds

- Resistance measurement

- Gain measurement

- Summary 


\section{The MCP detector}

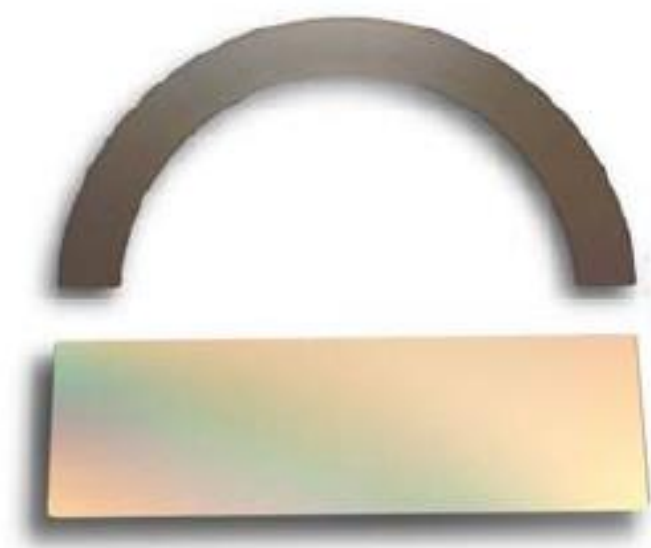

CHANNEL

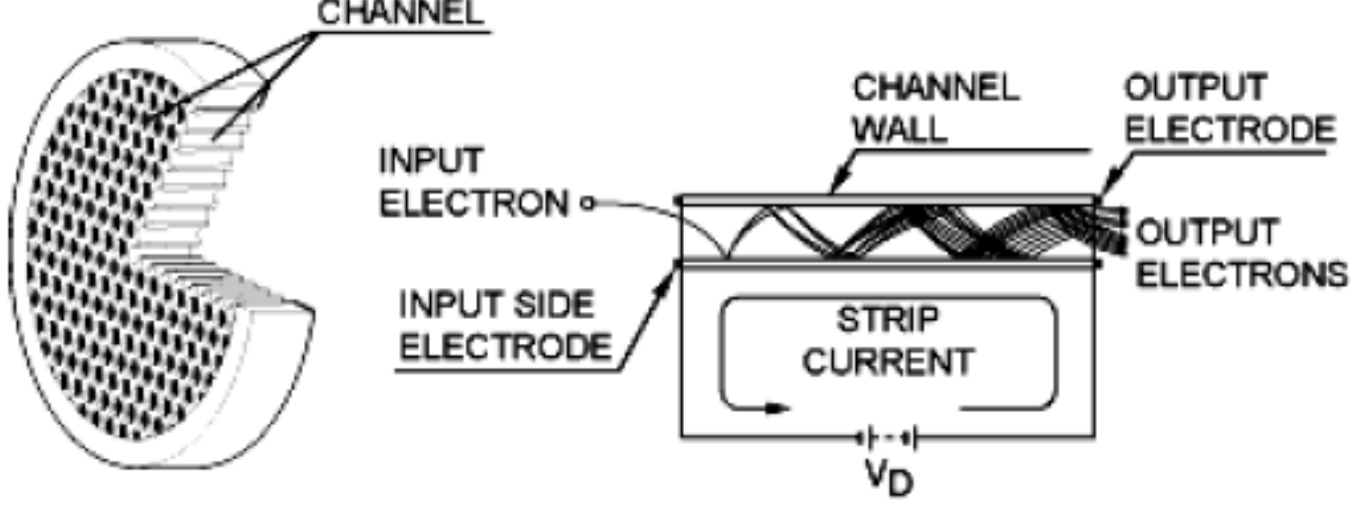

Z-stack

Chevron

Single plate

MIIIIIU

Gain $>1^{\mathrm{E} 3}$

\section{MIIIIIIIIV}

ZIIIIIIII

Gain $>1^{\mathrm{E} 6}$

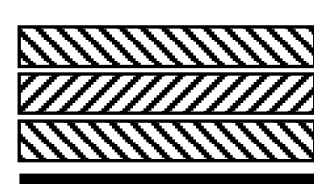

Gain $>1^{\mathrm{E} 8}$

- Space grade MCP manufacturers:

- Hamamatsu

- Photonis France

- Photonis USA 


\section{Motivations}

\section{Qirap}

- MCPs have been the subject of several studies, most of which focus on their lifetime or detection efficiency.

- However, only a few of these studies deal with the variation of their resistance or gain with temperature.

- This contrasts with the number of applications where temperature variations can be significant especially in the space environment.

- Usually, space instruments are calibrated on the ground under the room temperature.

- Therefore, it is very important to know the properties of the MCP detector with temperature to determine its behavior once in flight. 


\section{Backgrounds}

- The table below lists some studies available in the literature on the variation of the resistance or the gain of the MCP detector with temperature.

\begin{tabular}{c|ccc}
\hline Authors & Parameter & Temperature range & Type of study \\
\hline J. F. Pearson et al. & Resistance & $290-305 \mathrm{~K}$ & Estimation \\
P. Roth and G. W. Fraser & $"$ & $4-278 \mathrm{~K}$ & Measurement \\
A. S. Tremsin et al. & $"$ & $256-321 \mathrm{~K}$ & $"$ \\
Slater and Timothy & Gain & $313-433 \mathrm{~K}$ & $"$ \\
\hline
\end{tabular}

- The present study was curried out to meet the specific needs of the JENI (PEP package) instrument onboard of the ESA Jupiter Icy moon Explorer (JUICE) mission, where very low temperature conditions are expected around Jupiter. But, this study can be useful to other missions. 


\section{ESA Solar System missions}

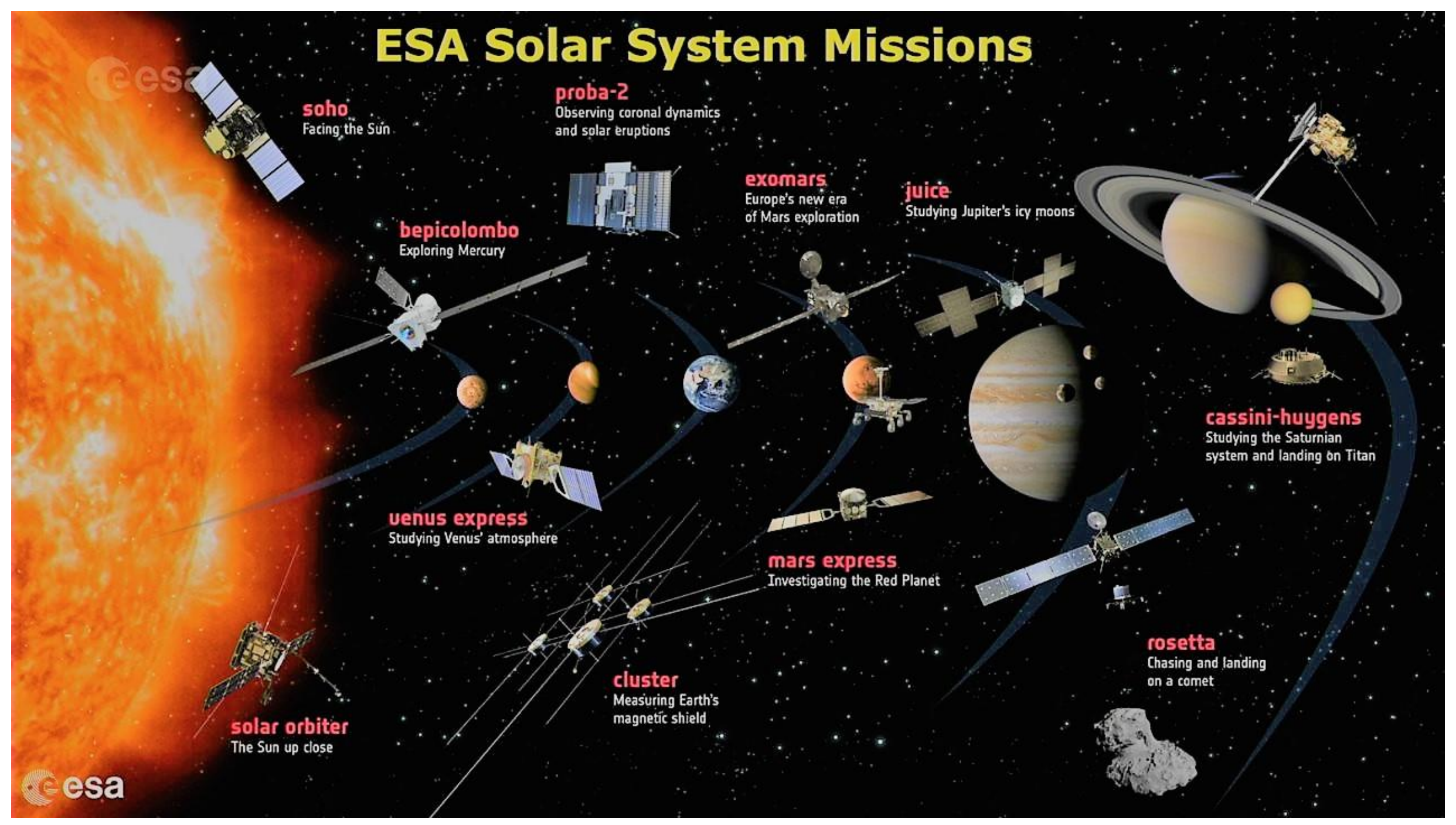




\section{Overview of the test facilities}

INTRASPEC TECHNOLOGIES test bench

IRAP CALIPSO-3 test bench
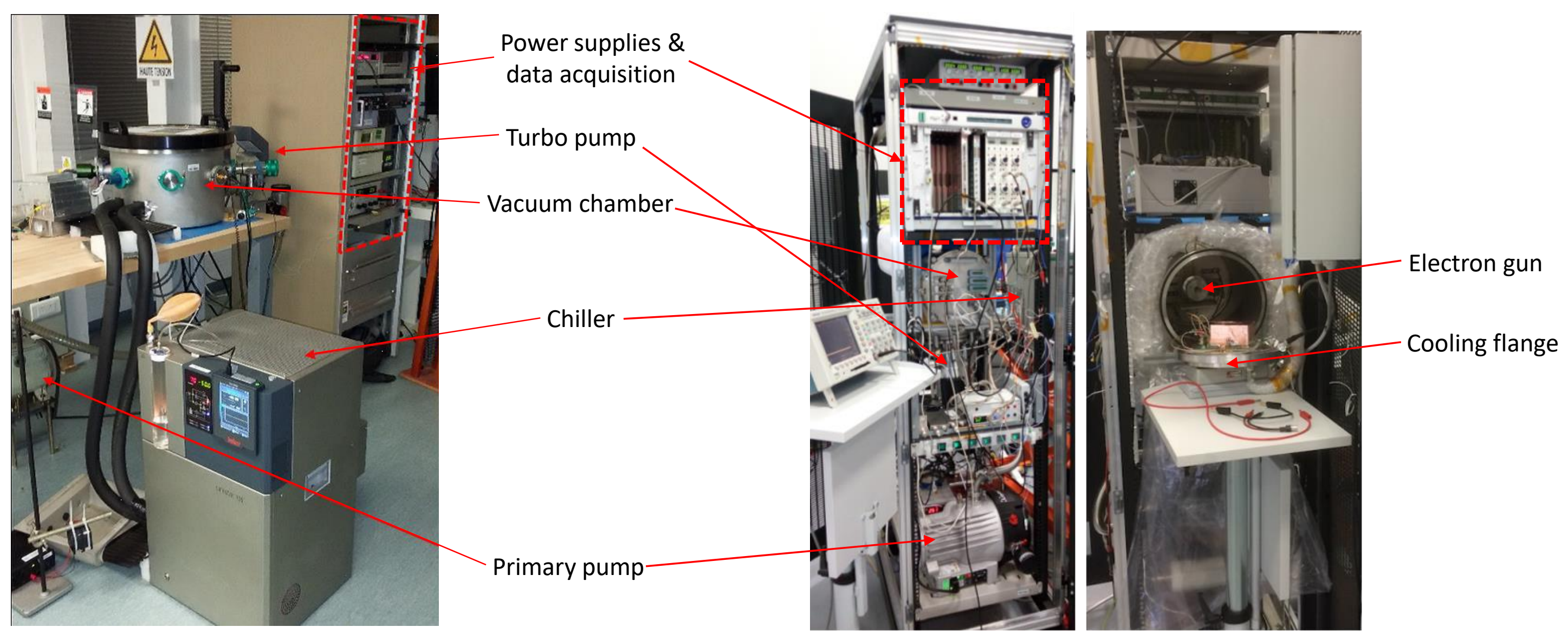


\section{Characteristics of test equipment}

INTRASPEC TECHNOLOGIES test bench

- A vacuum chamber:

- Vacuum capacity $<5$ e-7 mbar

- A thermal exchanger

- A PID-controlled Peltier cells module

- A 0-20 kV power supply

- A picoammeter

- Eight thermocouples

- A Chiller:

- Cooling capacity: $0.3 \mathrm{~kW}$ at $-75^{\circ} \mathrm{C}$

- Temperature range: $-75 /+60{ }^{\circ} \mathrm{C}$
IRAP CALIPSO-3 test bench

- A vacuum chamber with an $\mathrm{e}^{-}$gun

- Vacuum capacity < 1e-7 mbar

- A customized cooling flange

- A Peltier element

- Five 0-5 kV power supplies

- 8-channel MCA

- 16-channel DAC

- 16-channel counter

- Three thermocouples

- A Chiller

- Cooling capacity: $1 \mathrm{~kW}$ at $-40^{\circ} \mathrm{C}$

- Temperature range: $-40 /+80{ }^{\circ} \mathrm{C}$ 


\section{Resistance measurement}

- We performed the resistance measurement using unscrubbed MCPs from PHOTONIS France in chevron configuration with a bias of $2 \mathrm{kV}$ and using small and large plates taken from two different batches to assess the influence of the self-heating effect. The characteristics of these MCPs are given in the table below.

\begin{tabular}{c|ccccc}
\hline \multirow{2}{*}{ Batch \# } & $\begin{array}{c}\text { Thickness L } \\
(\mathbf{m m})\end{array}$ & $\begin{array}{c}\text { Pore size D } \\
(\boldsymbol{\mu m})\end{array}$ & $\begin{array}{c}\text { Bias angle } \\
(\mathbf{d e g r e e s})\end{array}$ & $\begin{array}{c}\text { Dimension } \\
\left(\mathbf{m m}^{\mathbf{2}}\right)\end{array}$ & $\begin{array}{c}\text { Resistance } \\
(\mathbf{M} \boldsymbol{\Omega})\end{array}$ \\
\hline \multirow{2}{*}{1} & 1.5 & 25 & 12 & $18 \times 18$ & 1000 \\
& $"$ & $"$ & $"$ & $58 \times 90$ & 52 \\
\hline \multirow{2}{*}{2} & $"$ & $"$ & $"$ & $18 \times 18$ & 300 \\
& $" \prime$ & $"$ & $"$ & $48 \times 140$ & 14 \\
\hline
\end{tabular}




\section{Test Setup}

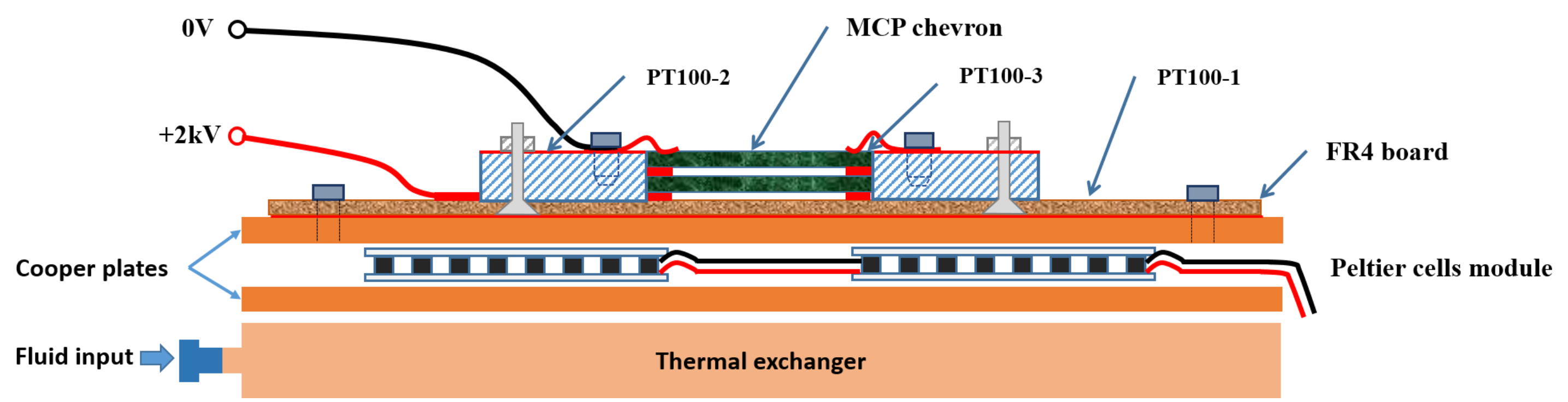




\section{Gain measurement}

\section{Qirap}

- We performed the gain measurement using MCP samples from PHOTONIS France and from PHOTONIS USA which share the same L, D and bias angle parameters in chevron configuration.

- Each MCP chevron was taken from different batches dedicated for the JENI instrument onboard of JUICE and was scrubbed to extract an accumulated charge of $30 \mathrm{mC} / \mathrm{cm}^{2}$.

- The gain was measured through a statistical approach to take into account a slight drift $\left( \pm 0.005 \% /{ }^{\circ} \mathrm{C}\right)$ of the MCPs bias around $2 \mathrm{kV}$ with temperature. 


\section{Test setup}

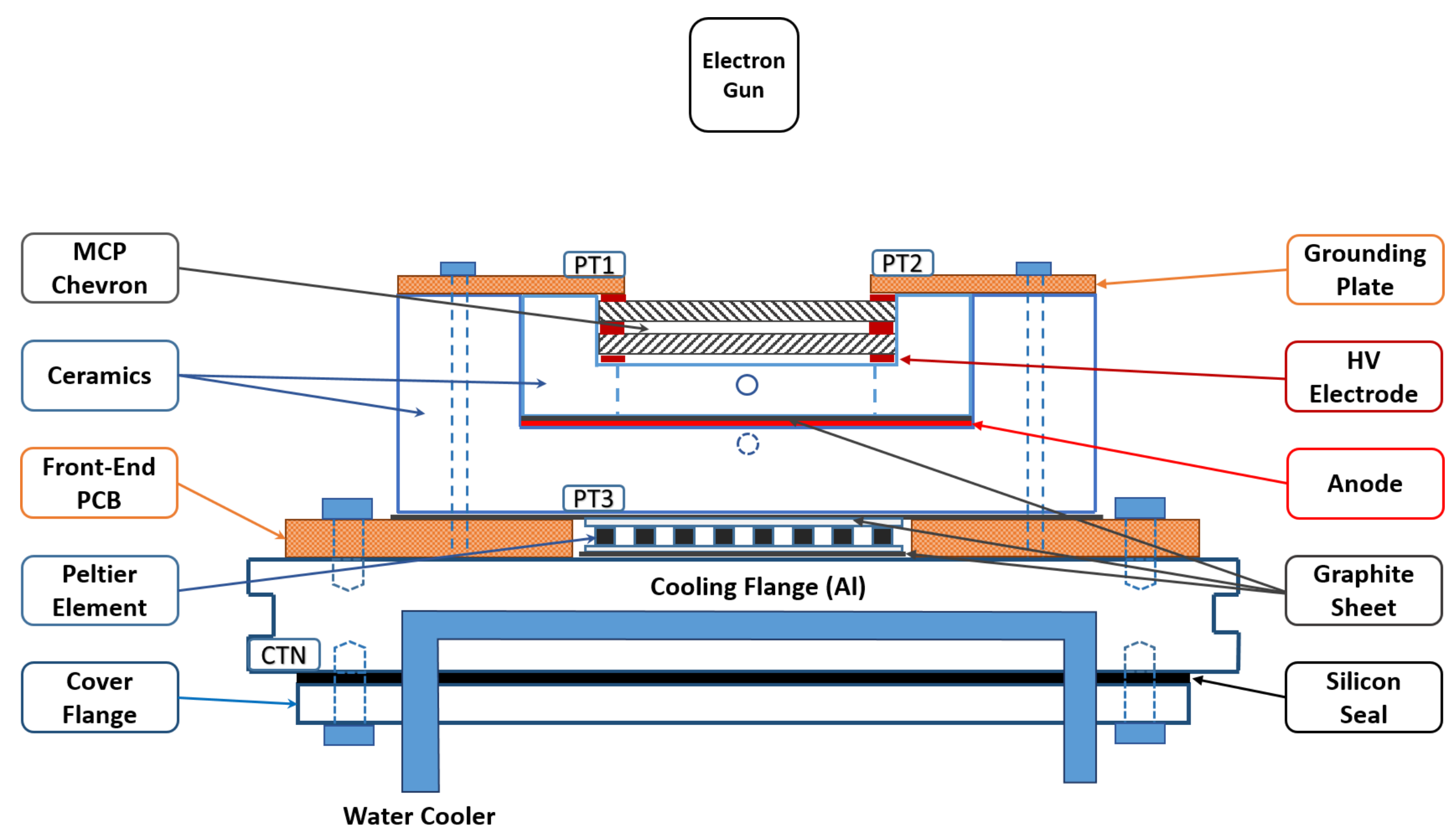




\section{Views of the setup parts}
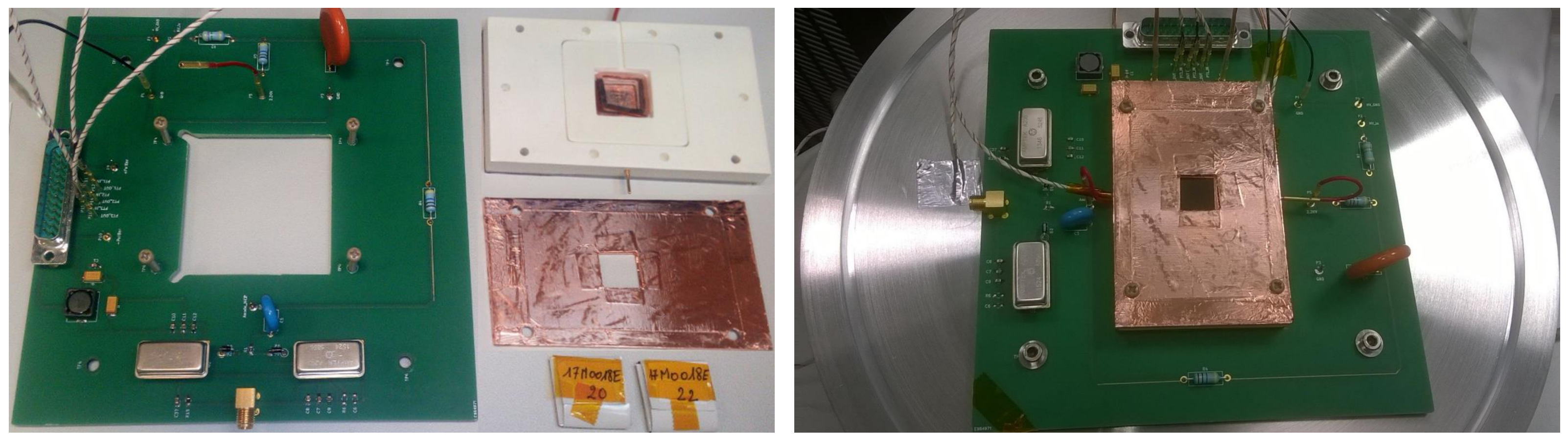


\section{Summary}

- The variation of the resistance of the MCP detector with temperature is exponential for small MCPs and polynomial for large MCPs due to the self-heating effect. Since the resistance of the MCP detector is an important parameter, at least for the design off the high voltage power supplies, it is preferable to characterize it using full-size MCPs in their final configuration.

- The gain of the MCP detector can increase when the temperature decreases depending on its technology. Since the background noise in the Jovian environment represents a crucial issue for the JENI MCPs, these experimental results can be used to optimize their gain performance and lifetime.

- These tests can be easily adapted to any other space experiment using MCP detectors. 


$$
\text { Thank you ! }
$$

